The London County Council has approached the Building Research Station on the subject of fire risks, and the testing of materials for fire resistance, necessarily a matter involving considerable capital cost, is being debated with firms interested in the production of such materials. For experiments on the heating of buildings it is proposed to construct a special house where walls, floors and ceilings would be capable of thermal control, while for the prediction of sunlight obtainable by any room in a proposed house a simple instrument, the 'helidon', has been designed. The difficult problem of excluding damp from dwellings has been further investigated, and it would appear that a large number of specifics for treating walls to prevent the entrance of moisture are of very small value. Much remains to be done on this subject, but it seems likely that some means of allowing moisture to evaporate externally is more promising as a solution than attempts to render walls wholly impervious.

In connexion with the weathering of stones, the work of the Station on the selection of stone for repairs to the Houses of Parliament will be remem. bered, and now a survey of building stone resources is being undertaken in collaboration with H.M. Geological Survey, nearly 150 samples of Portland stone having been examined during the past year. The selection of suitable stone for building has, as is too well known from examples of decay, a very marked bearing on the ultimate cost of upkeep, and as this decay is due to many diverse agencies which operate very unequally in different localities, the acquisition of adequate knowledge requires prolonged investigation.

This survey by no means exhausts the account of the work done during the year by the Building Research Board, as indicated in the 150 pages of the Report, but is sufficient to show the contribution which the Research Station is making to bring the appreciation of the fruits of science home to the architect and industrialist and to indicate how such knowledge can be turned to practical account.

\title{
Physics in Meteorology
}

TWHE eighteenth lecture of the "Physics in Industry" series founded by the Institute of Physics was delivered on November 2 by Dr. G. C. Simpson, Director of the Meteorological Office, who took as his subject "Physics in Meteorology." Dr. Simpson said that meteorology is mainly applied physics; every branch of physics finds an application in it and he described five recent meteorological investigations which have respectively depended on an application of sound, light, heat, magnetism and electricity.

When large and violent explosions occurred it was noticed that the sound was loudest near the origin and then decreased, as one would expect, until at a certain distance, about sixty miles, it could no longer be heard. The surprising observation, however, was made that at still greater distances, more than 120 miles, the sound was again audible. After the War, much work was done to try to find an explanation of this curious effect. In Great Britain, Dr. F. J. W. Whipple of Kew Observatory organised an investigation and records were obtained at Sheffield, Birmingham, Bristol, Nottingham and Cardiff of the sounds made when large guns were fired in Shoeburyness, near the mouth of the Thames. The result of this work has shown that the old idea that the upper atmosphere-the stratosphere-is cold throughout, can no longer be held. The stratosphere is cold up to a height of about 25 miles and then it becomes warm again and at great heights becomes even warmer than at the surface.

The theory of optics has been used very much in meteorology especially to determine whether clouds are composed of water or ice, but recently spectroscopy has been used by Dr. G. M. B. Dobson, of Oxford, to investigate the amount of ozone present in the upper atmosphere. He finds that, while there is practically no ozone lower than 30 miles above the surface, at greater heights there is a relatively large quantity and it is the presence of this ozone which makes the upper atmosphere warm. A very unexpected result has come out of this work, for Dr. Dobson shows that the ozone is not uniformly distributed, but is concentrated in the neighbourhood of cyclonic depressions and is relatively weak in the neighbourhood of anticyclones. How cyclones and anticyclones, which are known to be phenomena of the lower atmosphere, can effect the amount of ozone 30 miles up in the atmosphere, or whether it is the other way about and the ozone causes the cyclones, are problems which cannot yet be solved.

For his example of the application of the physics of heat to meteorology, Dr. Simpson described some of his own work on the balance of incoming and outgoing radiation. Heat reaches the earth as short. wave radiation from the sun and leaves again as long-wave radiation from the upper atmosphere. The incoming radiation is much greater in equatorial than in polar regions, thus accounting for the difference of temperature between the equator and the poles. Calculations, however, show that the outgoing radiation is practically the same from all parts of the earth, and the poles send as much radiation into outer space as do the equatorial regions. As the polar regions send out much more heat than they receive from the sun, the loss has to be made up by transfer of heat from low to high latitudes. It is the transfer of this heat which is the driving force of the winds.

Magnetism has not much direct effect on the atmosphere and, therefore, does not enter much into meteorology : but in most countries the study of the natural magnetism of the earth-terrestrial magnetism--is part of the duty of meteorologists, and in Great Britain two of the chief observatories where terrestrial magnetism is studied are under the control of the Meteorological Office. Terrestrial magnetism is known to be greatly affected by the activity of the sun and so is the atmosphere, but it has always been difficult to find any relationship between terrestrial magnetism and the atmosphere. Recently, however, Mr. J. M. Stagg, who is at present in charge of the British Polar Year Expedition to Fort Rae in Canada, has found an interesting rela. tionship at Aberdeen between magnetic activity and the barometric pressure. This relationship, however, must be examined further before it can be shown to be real.

Electricity, unlike magnetism, plays an important part in meteorology, especially in thunderstorms. Dr. Simpson, however, discussed another aspect of

No. 3288, Vol. 130] 
atmospheric electricity and described the electrical field which always exists even in fine weather near the earth's surface. He said that this field is probably due to the fact that the conducting layers in the upper atmosphere, the so-called KennellyHeaviside and Appleton layers, are maintained at a potential of several million volts above ground potential. How the difference of potential is maintained is one of the main problems of atmospheric electricity. Prof. C. T. R. Wilson considers that thunderstorms are the cause, while others consider that some solar effect is responsible because the potential is highest each day when the earth's north magnetic pole points most directly towards the sun. In conclusion, Dr. Simpson described some recent experiments at Kew Observatory which indicate that the ionisation of the lower atmosphere is not uniform, but that the ions occur in parcels. This observation is likely to have an important bearing on the theory of the ionisation of the atmosphere.

\section{University and Educational Intelligence}

Bristol.-Mr. N. F. Mott, lecturer in mathematics in the University of Cambridge, has been elected to the Melville Wills chair of theoretical physics in the University of Bristol in succession to Prof. J. E. Lennard-Jones. By agreement with the University of Cambridge, Prof. Lennard-Jones will give assistance to the Wills Laboratory during the present session and Mr. Mott will not take up his duties until next autumn.

Dr. C. M. Yonge, of the Marine Biological Laboratory, Plymouth, has been appointed to the chair of zoology in the University.

Cambridge.-Dr. Drury has been appointed Huddersfield lecturer in special pathology. J. S. Turner, of Selwyn College, has been appointed to the Frank Smart University studentship in botany.

Sir James Jeans will deliver the Henry Sidgwick memorial lecture on November 26 at 5 P.M. in the College Hall, Newnham College. The subject of the lecture is "The Furthest Depths of Space".

LONDON.-In consequence of the announcement that Major the Hon. John J. Astor, M.P., was the anonymous donor in 1920 of the gift of $£ 20,000$ for the endowment of the University chair of physiology at the Middlesex Hospital Medical School, it has been decided that the title of this chair shall now be the "John Astor Chair of Physiology tenable at the Middlesex Hospital Medical School". As recently announced, a gift of $£ 1,500$ a year for seven years has been promised by the Prudential Assurance Company for the endowment of the chair of public health tenable at the London School of Hygiene and Tropical Medicine; it has been decided that the chair shall be known as the "Prudential Chair of Public Health" for the duration of the gift.

The title of emeritus professor of mathematics in the University has been conferred on Prof. S. A. F. White, on his retirement from the chair of mathematics at King's College.

Manchester.-Dr. John Hollingworth has been appointed to succeed Prof. Miles Walker, who has held the chair of electrical engineering in the University and College of Technology since 1912. Prof. Miles Walker's many services to electrical engineering are well known; in Manchester he will be remembered for the close association of the engineering industry and the University which he has been instrumental in bringing about. Dr. Hollingworth was educated at Bradfield College, University College (London), Peterhouse (Cambridge) and the City and Guilds Engineering College. He was a wrangler at Cambridge in 1907, and has since held various appointments both industrial and academic. Prior to 1917 his experience was all in heavy engineering; since that date he has been engaged in radio research.

The following appointments have also been made : Demonstrator in anatomy, Mr. A. N. Birkett; demonstrators in pharmaceutics, Dr. Kenneth Bullock and Mr. S. L. Prescott; lecturer in mathematics (College of Technology), Mr. James Topping; assistant lecturer in metallurgy and assaying (College of Technology), Mr. E. A. Fowler; demonstrator in physics (College of Technology), Mr. Joseph Bor.

Mr. C. J. P. D. La Touche has resigned his post as research assistant in mycology on his appointment as lecturer in botany in University College, Dublin.

The Council has accepted from Mrs. R. W. Williamson a portrait in oils of her father-in-law, the late Prof. W. C. Williamson, who was in charge of the teaching of zoology, botany and geology in Owens College from 1851 until 1892.

The thirty-third annual meeting of the Science Master's' Association will be held at the University of Bristol on January 3-6, 1933, under the presidency of Prof. A. M. Tyndall, who will deliver an address on "Gaseous Ions". Several lectures have also been arranged to be given by members of the staff of the University. Further information can be obtained from the Annual Meeting Secretary, Shirley Hill, Boden Road, Hall Green, Birmingham.

\section{Calendar of Geographical Exploration}

\section{Nov. 8, rg03.-An Antarctic Rescue}

Capt. Irizar rescued Otto Nordenskiöld and his party. Dr. O. Nordenskiöld, nephew of the hero of the Vega expedition, with C. A. Larsen and J. Gunnar Andersson, left Göteborg on October 16, 1901, for research work in the antarctic. His vessel was off the South Shetlands in 1902 and proceeded down the west coast of Louis Philippe Land, discovering that the Orleans channel did not reach Weddell Sea, but was merely a part of Gerlache Strait. On February 12 Nordenskiöld, three scientific workers and two sailors, landed on Snow Hill Island in $64^{\circ} 25^{\prime} \mathrm{S}$. and established winter quarters. The ship went north to carry on researches in the open sea. She did not return in spring as expected and the party was compelled to spend a second winter, during which the insularity of Ross Island was established. In Oetober, 1903, Nordenskiöld encountered Andersson and a companion, black from head to foot and with long black hair and bushy beards, so that they were at first not recognisable. They had left the ship when it became clear that she could not reach the winter camp and had set out on foot, eking out their scanty diet with seal oil. On November 8, Capt. Irizar of the Argentine naval vessel, Uruguay, reached Snow Hill Island and, that night, by an extraordinary coincidence, Larsen and the crew also arrived. The ship had been caught in the ice in Erebus and Terror Gulf in January and so

No. 3288 , VoL. 130] 